Review

\title{
Platelet-derived Extracellular Vesicles: An Emerging Therapeutic Approach
}

\author{
Shi-Cong Tao ${ }^{1}$, Shang-Chun Guo ${ }^{2 \bowtie}$, Chang-Qing Zhang ${ }^{1,2} \bowtie$ \\ 1. Department of Orthopedic Surgery, Shanghai Jiao Tong University Affiliated Sixth People's Hospital, 600 Yishan Road, Shanghai 200233, China; \\ 2. Institute of Microsurgery on Extremities, Shanghai Jiao Tong University Affiliated Sixth People's Hospital, 600 Yishan Road, Shanghai 200233, China. \\ $\triangle$ Corresponding authors: Chang-Qing Zhang, Department of Orthopedic Surgery, Shanghai Jiao Tong University Affiliated Sixth People's Hospital, Shanghai \\ 200233, China. E-mail: zhangcq@sjtu.edu.cn Shang-Chun Guo, Institute of Microsurgery on Extremities, Shanghai Jiao Tong University Affiliated Sixth People's \\ Hospital, 600 Yishan Road, Shanghai 200233, China. E-mail: achuni@126.com \\ (c) Ivyspring International Publisher. This is an open access article distributed under the terms of the Creative Commons Attribution (CC BY-NC) license \\ (https://creativecommons.org/licenses/by-nc/4.0/). See http://ivyspring.com/terms for full terms and conditions.
}

Received: 2017.02.22; Accepted: 2017.04.30; Published: 2017.07.06

\begin{abstract}
Extracellular vesicles (EVs) are a newly-discovered way by which cells communicate with their neighbors, as well as transporting cargos which once were considered to be limited by membrane barriers, including membrane proteins, cytosolic proteins and RNA. The discovery of platelet-derived EVs (P-EVs), the most abundant EVs in human blood, has been a very tortuous process. At first, P-EVs were identified as nothing but 'platelet dust', and subsequent research did not progress smoothly because of the limited research techniques to study EVs. Following leaps and bounds of technical progress in studying EVs, more and more attractive features of P-EVs were revealed and they began to be further researched. The aim of this review is to present the latest knowledge about the role of P-EVs in tissue repair and tumor progression. The potential mechanism of P-EVs is emphasized. Then the limitations of the present study and future research directions are discussed.
\end{abstract}

Key words: extracellular vesicle; micro-vesicle; exosome; platelet; regenerative medicine; platelet-rich plasma.

\section{Introduction}

Platelets, the anuclear components of blood, play an important role in hemostasis and thrombosis [1]. In classic theories, platelets were regarded simply as fragments of megakaryocytes (MKs) with no synthetic capabilities. After subsequent studies showed that new proteins could be synthesized by platelets [2], this prejudice disappeared. Extracellular vesicles (EVs) have since been found to play a considerable role in the biological function of activated platelets $[3,4]$.

EVs transport cargos, which once were considered to be limited by the membrane barrier, including membrane proteins, cytosolic proteins, messenger RNA (mRNA), microRNA (miRNA), long non-coding RNA (lncRNA), and circular RNA (circRNA) [5]. EVs can regulate signaling pathways via receptor-ligand interactions or content delivery, after attachment to or internalization by recipient cells [6].
Wolf was the first to observe the 'lipid-rich particles' released from platelets [7], now known as platelet-derived EVs (P-EVs), and the release of P-EVs from activated platelets was described in more detail by Warren et al. [8]. However, in-depth research was limited for years due to the lack of understanding of EVs. As research progressed, the abundant knowledge reserves and advanced research methods now applicable to EVs are certainly enough to support their further study.

EVs, including exosomes $(30-100 \mathrm{~nm}$ in diameter) and micro-vesicles (MVs, sometimes called microparticles or ectosomes, 100-1,000 nm in diameter) [6], exist in almost all biological fluids carrying multifarious molecules such as proteins, lipids, and RNAs either on their surface or within their lumen [9]. They are generated and released from nearly all cell types into the extracellular space [10]. EVs have gained increasing attention for the past 
decade as potential biomarkers. The biomolecules carried by EVs, including proteins, nucleic acids and lipids, are reflective of the cell of origin [11]. Although the distinguishing characteristics of EVs in blood still remain unclear, some specific features have been identified, such as prostate-specific antigen on exosomes in urine from patients as markers of prostate cancer-derived EVs [12], claudin on exosomes in peripheral blood as markers of ovarian cancer [13], and several potential markers including CD31, CD41, CD42a, CD62p (P-selectin), platelet factor 4 (PF4) and glycoproteins IIb/IIIa (GPIIb/IIIa) as markers of platelet-derived EVs[14].

Recent studies showed that, in human serum, most EVs are P-EVs, although EVs can also be generated from white blood cells and cancer cells [15-17]. P-EVs have been found to participate in a variety of important biological and pathological processes via intracellular communication [18, 19], including clotting [20, 21], angiogenesis [22, 23], inflammation [24, 25], immunoregulation [3], cellular prion protein transport [26], and tumor progression $[25,27]$.

In this review, the relationship between P-EVs and cancer progression, as well as potential therapeutic approaches related to P-EVs, are addressed.

\section{Extracellular Vesicles}

In recent years, there have been a lot of inspiring discoveries involving EVs, revealing them to be a brand new way by which cells communicate with their neighbors [28]. Although there were once some skeptical opinions that EVs might be operator-induced artefacts created during isolation procedures, there is a growing recognition that EVs are derived from cells, rather than being products of human actions during the isolation process, and participate not only in physiology and homeostasis, but also in the pathogenesis of major diseases [25]. EVs are produced, theoretically, by every kind of cell and are present in every kind of body fluid including blood, saliva, urine, cerebrospinal fluid, breast milk and semen [29].

EVs usually are divided into two classes: exosomes (30-100 $\mathrm{nm}$ in diameter) and MVs (100-1,000 nm in diameter) [6]. Exosomes are of endosomal origin and are released during the fusion of multi-vesicular bodies (MVBs) to the plasma membrane, and the traditional model is that this occurs in an endosomal sorting complex required for transport (ESCRT)-dependent manner [30]. The exosomes are formed with the participation of tetraspanins (CD9, CD63), tumor susceptibility gene 101 (TSG101), and programmed cell death 6-interacting protein (PDCD6IP or ALIX) [31, 32]. Consequently, these proteins are usually chosen as specific markers of exosomes. MVs are released by budding from the plasma membrane [33] at specific membrane sites, named 'microdomains' [34]. Thus, the lipid-raft protein, flotillin, is a frequently-used marker of MVs [35]. It is necessary to distinguish EVs from apoptotic bodies (0.8-5.0 $\mu \mathrm{m}$ in diameter), which are shed by apoptotic cells, and are regarded as irrelevant to intercellular communication because they will be eliminated by phagocytes immediately after generation [36].

\section{Platelet-derived Extracellular Vesicles}

The most abundant EVs in human blood are derived from platelets or MKs, accounting for more than half of all EVs in the peripheral blood [37, 38]. With the help of electron microscopy (EM), Wolf initially indicated the presence of membrane fragments or 'lipid-rich particles' derived from activated platelets, which he named 'platelet dust', now recognized as P-EVs, and having procoagulant activity [7]. Based on this milestone in the study of P-EVs, Warren et al. further demonstrated that the P-EVs were released when platelets attached to the vascular wall [8].

In 1999, Heijnen et al. reported that P-EVs comprised two different types: exosomes (P-Exos) and MVs (P-MVs) [39]. Isolated P-Exos were selectively enriched in tetraspanin CD63, an exosome-specific marker, while annexin- $\mathrm{V}$, factor $\mathrm{X}$ and prothrombin were restricted to P-MVs and not P-Exos [39]. Both P-Exos and P-MVs are known to carry and deliver cellular signals, suggesting a potential role in platelet-derived signals [40]. Moreover, P-MVs might play a greater role in procoagulant activity than P-Exos [39].

Several potential markers have been detected on P-EVs, with expression of CD31, CD41, CD42a, P-selectin, PF4 and GPIIb/IIIa detected besides markers of EVs [14]. A summary of the characteristics of P-EVs is provided in Table 1.

Table 1. Summary of the characteristics of P-EVs.

\begin{tabular}{lll}
\hline & P-Exos & P-MVs \\
\hline $\begin{array}{l}\text { Diameter } \\
\text { Origin }\end{array}$ & 30-100 nm & 100-1,000 nm \\
Production & Multi-vesicular bodies & $\begin{array}{l}\text { Plasma membrane } \\
\text { Budding from }\end{array}$ \\
$\begin{array}{l}\text { mechanism } \\
\text { Surface markers }\end{array}$ & CD9, CD63, TSG101, ALIX & 'microdomains' \\
$\begin{array}{l}\text { Platelet-specific } \\
\text { proteins }\end{array}$ & CD31, CD41, CD42a, P-selectin, & Factor X, prothrombin \\
\hline
\end{tabular}

The isolation procedure of P-EVs can be divided into 4 steps [41]: Step one, platelet-rich plasma (PRP) 
is extracted from whole blood; Step two, platelets are further isolated from PRP; Step three, platelets are activated to induce the release of EVs; Step four, EVs are isolated by differential centrifugation.

\section{Platelets: One of the Commanders of Tissue Repair}

Therapy using stem cells, including induced pluripotent stem cells (iPSCs), human embryonic stem cells (hESCs), mesenchymal stem cells (MSCs) and adipose stem cells (ADSCs), has been attempted for several years. However, clinical translation of these techniques was impeded due to difficulties such as issues of immune response and tumorigenesis [42]. Recent studies showed that major effects of cell transplantation are credited to the cells' paracrine effects (as a commander, Figure 1B) [43] rather than directed proliferation and differentiation after site-specific integration (as an executor, Figure 1A) $[44,45]$. Hence, to overcome these drawbacks, the use of EVs, rather than direct use of stem cells or progenitor cells for tissue repair, has attracted increasing attention in recent years [46, 47].

EVs, especially exosomes, have been extensively studied for their role in stimulating tissue regeneration, in many in vitro and in vivo models, demonstrating that they can confer proangiogenic, proliferative, antiapoptotic and anti-inflammatory actions through transporting RNA and protein cargos [47-51].

It is well known that PRP, a concentration of platelets in a small volume of plasma, is widely used to help with tissue repair [52]. However, the understanding of PRP-induced tissue repair is far from complete. With the increased knowledge of cell-derived EVs, the potential of P-EVs has attracted more and more attention (Figure 1C). After studies have revealed P-EV-induced activation of intracellular signaling pathways, alteration of vascular reactivity and induction of angiogenesis in cancer metastasis, it is highly likely that P-EVs may not only be involved in tumor progression, but also be useful for developing novel therapeutic strategies targeting angiogenesis for tissue repair [53].

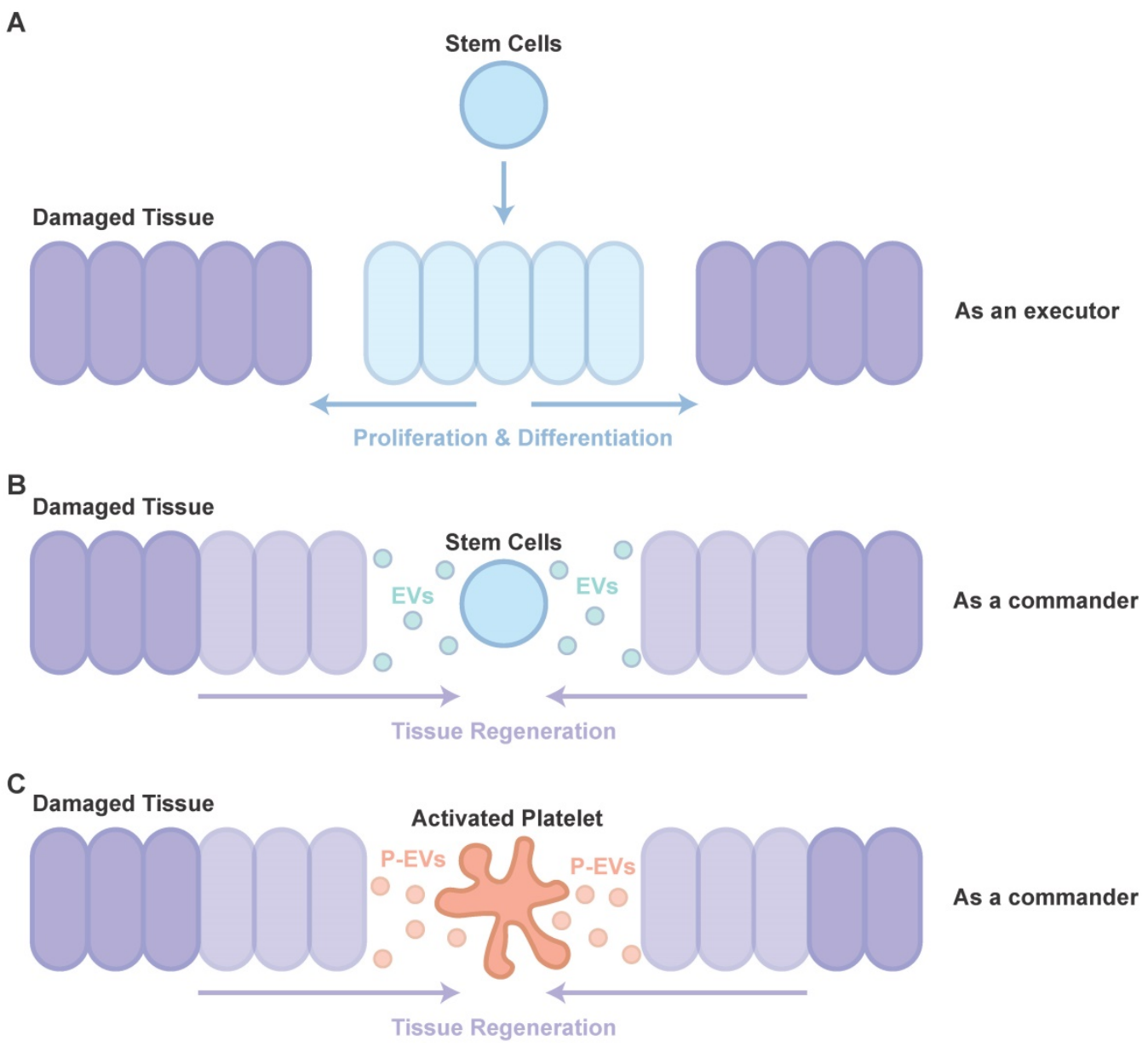

Figure 1. Participants in tissue repair. (A) The directed proliferation and differentiation of stem cells after site-specific integration. (B) The major effects of cell transplantation are credited to the cells' paracrine effects. (C) The role of P-EVs as important participants in PRP-induced tissue regeneration are similar to that of EVs in cell transplantation. 
Subsequent research proved that P-EVs indeed boosted angiogenesis to restore endothelial integrity after vascular injury [22]. Further, in cerebral ischemia, Hayon et al. indicated that P-EVs are filled with a variety of growth factors, associated with the Akt and Erk pathways, and are central to angiogenesis and neurogenesis, and demonstrated that P-EVs could trigger neurogenesis and angiogenesis in a stroke model, by augmenting endogenous neural progenitors and stem cells [54-56]. Then, Torreggiani et al. demonstrated that bone marrow stromal cells (BMSCs), treated with P-EVs with an enriched protein content and non-coding RNAs, showed a significant increase in cell proliferation, migration and osteogenesis [57]. Torreggiani et al. implied that P-EVs might be one of the effectors of the actions of PRP and platelet lysate [57]. Based on these findings, P-EVs were isolated and attempts were made to use them as a therapeutic approach to treat chronic wounds. They showed abilities, similar to PRP, to improve cell proliferation, migration and angiogenesis via phosphoinositide 3-kinase (PI3K)-Akt and mitogen-activated protein kinase (MAPK)-Erk signaling, and cross-talk between transforming growth factor $\beta$ (TGF- $\beta$ ) and yes-associated protein (YAP), leading to promotion of wound healing [58]. The result of this pre-clinical research is encouraging, because P-EVs might be both part of the mechanism of PRP-induced tissue regeneration and a potential alternative option instead of PRP. Moreover, P-EVs were used, in a pre-clinical study, to delay the disease progression of glucocorticoid-induced osteonecrosis of the femoral head [59], in which PRP was proven to be an effective approach [60, 61]. Although P-EVs exhibited the capacity to act as an alternative option or even to upgrade production of PRP, much clinical and pre-clinical research is still needed.

\section{Cancer cells: Hijacking the Platelet as a Renegade Commander}

Many studies have demonstrated that EVs play important roles in cancer development and progression, and P-EVs have attracted much attention [38]. The complicated relationship between cancer and thrombosis has progressively become established since Armand Trousseau, who first highlighted that thrombophlebitis is a premonitory sign of occult malignancy in 1865 [62]. In the 19 [th $^{\text {century, it was }}$ established that platelet reduction confers protection against cancer metastasis [63]. Later, the mechanism of tumor cell-platelet interaction, leading to aggregation of platelets, was gradually revealed [64].

The mechanisms underlying thrombocytosis in cancer and inflammation might be similar. Pro-inflammatory mediators, such as cytokines, increase platelet counts by stimulating MK formation and platelet production, and cancer cells could induce systemic effects such as promoting pro-inflammatory factors [65]. In addition, cancer-secreted PF4 has been demonstrated to expand megakaryopoiesis in the bone marrow, augment platelet accumulation, and then accelerate de novo carcinogenesis [66]. Cancer cells can also regulate platelet activation via the shedding of tumor-derived EVs (T-EVs), which are able to initiate thrombin generation [67]. In response to these deception signals from the cancer cells, the platelet, a tissue-repair commander, would be misled and become an accomplice of cancer progression, not only a carrier of transferred cancer cells but also a participant in the management, preparing suitable conditions for transfer.

Janowska-Wieczorek et al. showed that P-EVs could stimulate MAPK in lung carcinoma cell lines to promote proliferation, and increase matrix metalloproteinases (MMPs) to promote invasion [68]. Labelle et al. discovered that platelet-cancer interactions, via platelet-derived TGF- $\beta$, lead to epithelial-mesenchymal-like transition (EMT) which is a cellular phenotype that allows cancer cells to colonize distant organs [69].

Ironically, MAPK and cross-talk between TGF- $\beta$ and YAP has proved to be important in tissue repair induced by P-EVs [58]. In fact, cancer has often been equated to a wound that never heals, hijacking the body's natural ability for its malignant proliferation. The platelet's natural role in wound healing is therefore poised to be hijacked by cancer cells (Figure 2).

\section{Conclusions and Future Directions}

The observation of P-EVs has a long historical standing, but in-depth study was limited because of the poorly-developed techniques to study nano-sized vesicles. Along with technical progress in the study of EVs in general, P-EVs began to reveal their importance and attract the attention of more and more researchers.

PRP has long been known to be effective in promoting tissue repair but the underlying mechanism is still not fully understood. The discovery of P-EVs led to a more comprehensive and profound understanding. A recent study demonstrated that P-EVs had similar effects in wound healing to PRP [58]. It is likely that P-EVs might, in the near future, replace the use of PRP or become the next-generation PRP. 


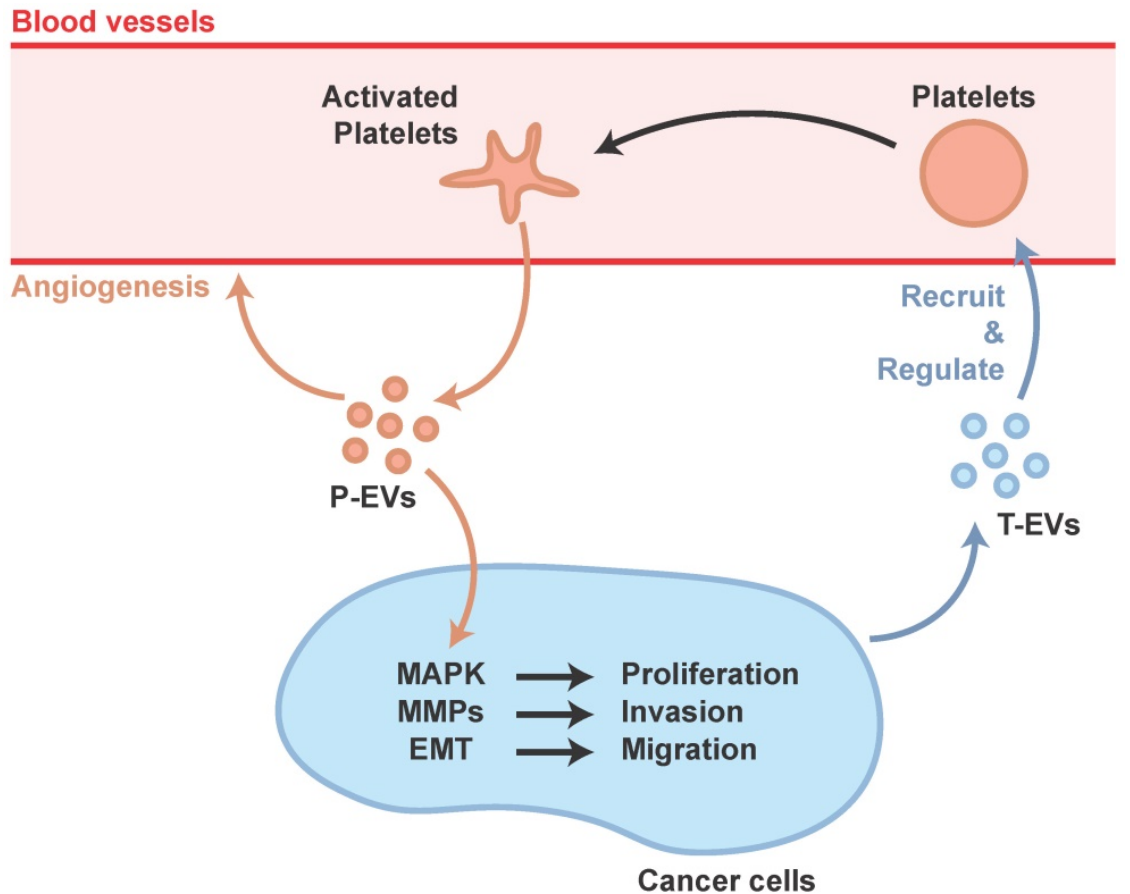

Figure 2. Participation of P-EVs in tumor progression.

Certainly, the analysis of P-EVs remains superficial. The function of carried RNA, which has a role in the functions of EVs, has not been sufficiently studied. For example, miR-126-3p, which is enriched in platelets [70] and is always involved in helping wound healing [71], might be one of the effectors of P-EVs, but lack of study means this has not been confirmed.

The suppression of cargo protein levels of plasma P-EVs caused by aspirin consumption [72] might explain why aspirin has proved useful in inhibiting the progress of cancer [73]. However, aspirin has several side effects including increased risk of bleeding, heavy menses, increased nausea and vomiting [74]. Although tamoxifen was found to be more focused on angiogenesis and malignancy [75], newly-designed drugs aimed at inhibiting the release of P-EVs caused by cancer cells, rather than the entire function of platelets, could have the prospect of broad application, because of the specific targeting of P-EVs related to tumor metastasis and the avoidance of influence on the coagulation function which results in several side effects. In addition, gene therapy to inhibit the uptake ability of P-EVs in cancer cells or the production and release ability of T-EVs which could recruit or regulate platelets, or immunotherapy targeting T-EVs to eliminate T-EVs in the blood circulation system, could also be potential future therapeutic approaches for the prevention of tumor metastasis.
The effects of P-EVs on tissue regeneration and cancer progression are inextricably linked. Not only are the underlying mechanisms in P-EV-induced tissue repair and cancer progression similar, but also if a cancer patient is accidentally injured, the safety of therapeutic usage of P-EVs may be compromised and should be given careful attention. The modification of exosomes has received extensive attention in both experiment and theory [76-78]. It is both possible and necessary to confer targeting abilities on P-EVs, which would promote tissue repair while having little influence on cancer progression, or enable targeted delivery of anti-cancer molecules without influencing tissue regeneration.

Despite the small size of P-EVs, they have numerous benefits including their ability to be released locally, their ease of travel through the body, their low immunogenicity, and the ease with which they can be obtained [58]. In addition it has been demonstrated that P-EVs participate in modulating signal transduction. In view of these findings, P-EVs might be not only a next-generation alternative to PRP but also a potential vehicle for the administration of drugs and other molecules, including mRNA, miRNA and IncRNA. They are likely to provide a better option than EVs derived from expensive stem cells or progenitor cells, to modulate cell activity in treating many disorders. However, to make P-EVs applicable and efficacious for treatment, their underlying functions still need to be better understood and the method of isolation still needs to be improved. 


\section{Acknowledgements}

This work was supported by the National Natural Science Foundation of China (Grant Nos. 81301589 and 81472066). This work was also supported by Joint Project Funding for Major Diseases in Shanghai (Grant No.2014ZYJB0301) and the NHFPC Special Fund for Health Scientific Research in the Public Welfare (NO. 201402016).

\section{Author Contributions}

Shi-Cong Tao planned and wrote this manuscript. Shang-Chun Guo helped with planning and writing. Chang-Qing Zhang gave basic advice and suggestions. All authors reviewed the manuscript.

\section{Competing Interests}

The authors have declared that no competing interest exists.

\section{References}

1. Gurbel PA, Jeong YH, Navarese EP, Tantry US. Platelet-Mediated Thrombosis: From Bench to Bedside. Circ Res. 2016; 118: 1380-91.

2. Schwertz H, Rowley JW, Tolley ND, Campbell RA, Weyrich AS. Assessing protein synthesis by platelets. Methods Mol Biol. 2012; 788: 141-53.

3. Dinkla S, van Cranenbroek B, van der Heijden WA, He X, Wallbrecher R, Dumitriu IE, et al. Platelet microparticles inhibit IL-17 production by regulatory T cells through P-selectin. Blood. 2016; 127: 1976-86.

4. Melki I, Tessandier N, Zufferey A, Boilard E. Platelet microvesicles in health and disease. Platelets. 2017: 1-8.

5. Raposo G, Stoorvogel W. Extracellular vesicles: exosomes, microvesicles, and friends. J Cell Biol. 2013; 200: 373-83.

6. Tkach M, Thery C. Communication by Extracellular Vesicles: Where We Are and Where We Need to Go. Cell. 2016; 164: 1226-32.

7. Wolf $\mathrm{P}$. The nature and significance of platelet products in human plasma. Br J Haematol. 1967: 13: 269-88.

8. Warren BA, Vales $\mathrm{O}$. The release of vesicles from platelets following adhesion to vessel walls in vitro. Br J Exp Pathol. 1972; 53: 206-15.

9. Kibria G, Ramos EK, Lee KE, Bedoyan S, Huang S, Samaeekia R, et al. A rapid, automated surface protein profiling of single circulating exosomes in human blood. Sci Rep. 2016; 6: 36502

10. Zhang J, Li S, Li L, Li M, Guo C, Yao J, et al. Exosome and exosomal microRNA: trafficking sorting and function. Genomics Proteomics Bioinformatics. 2015; 13: 17-24.

11. Nawaz M, Camussi G, Valadi H, Nazarenko I, Ekstrom K, Wang X, et al. The emerging role of extracellular vesicles as biomarkers for urogenital cancers. Nat Rev Urol. 2014; 11: 688-701.

12. Mitchell PJ, Welton J, Staffurth J, Court J, Mason MD, Tabi Z, et al. Can urinary exosomes act as treatment response markers in prostate cancer? J Transl Med. 2009; $7: 4$

13. Li J, Sherman-Baust CA, Tsai-Turton M, Bristow RE, Roden RB, Morin PJ. Claudin-containing exosomes in the peripheral circulation of women with ovarian cancer. BMC Cancer. 2009; 9: 244.

14. Antwi-Baffour S, Adjei J, Aryeh C, Kyeremeh R, Kyei F, Seidu MA. Understanding the biosynthesis of platelets-derived extracellular vesicles. Immun Inflamm Dis. 2015; 3: 133-40.

15. Brisson AR, Tan S, Linares R, Gounou C, Arraud N. Extracellular vesicles from activated platelets: a semiquantitative cryo-electron microscopy and immuno-gold labeling study. Platelets. 2017: 1-9.

16. Krafft C, Wilhelm K, Eremin A, Nestel S, von Bubnoff N, Schultze-Seemann $\mathrm{W}$, et al. A specific spectral signature of serum and plasma-derived extracellular vesicles for cancer screening. Nanomedicine. 2016.

17. Nazimek K, Ptak W, Nowak B, Ptak M, Askenase PW, Bryniarski K Macrophages play an essential role in antigen-specific immune suppression mediated by T CD $8(+)$ cell-derived exosomes. Immunology. 2015; 146: 23-32.

18. Risitano A, Beaulieu LM, Vitseva O, Freedman JE. Platelets and platelet-like particles mediate intercellular RNA transfer. Blood. 2012; 119: 6288-95.

19. Laffont B, Corduan A, Ple H, Duchez AC, Cloutier N, Boilard E, et al. Activated platelets can deliver mRNA regulatory Ago2*microRNA complexes to endothelial cells via microparticles. Blood. 2013; 122: 253-61.

20. Tafelmeier M, Fischer A, Orso E, Konovalova T, Bottcher A, Liebisch G, et al. Mildly oxidized HDL decrease agonist-induced platelet aggregation and release of pro-coagulant platelet extracellular vesicles. J Steroid Biochem Mol Biol. 2016.

21. Midura EF, Kuethe JW, Rice TC, Veile R, England LG, Friend LA, et al. Impact of Platelets and Platelet-Derived Microparticles on Hypercoagulability Following Burn Injury. Shock. 2016; 45: 82-7.

22. Mause SF, Ritzel E, Liehn EA, Hristov M, Bidzhekov K, Muller-Newen G, et al. Platelet microparticles enhance the vasoregenerative potential of angiogenic early outgrowth cells after vascular injury. Circulation. 2010; 122: 495-506.

23. Prokopi M, Pula G, Mayr U, Devue C, Gallagher J, Xiao Q, et al. Proteomic analysis reveals presence of platelet microparticles in endothelial progenitor cell cultures. Blood. 2009; 114: 723-32.

24. Boilard E, Nigrovic PA, Larabee K, Watts GF, Coblyn JS, Weinblatt ME, et al. Platelets amplify inflammation in arthritis via collagen-dependent microparticle production. Science. 2010; 327: 580-3.

25. Cocucci E, Racchetti G, Meldolesi J. Shedding microvesicles: artefacts no more. Trends Cell Biol. 2009; 19: 43-51.

26. Robertson $\mathrm{C}$, Booth $\mathrm{SA}$, Beniac DR, Coulthart MB, Booth TF, McNicol A. Cellular prion protein is released on exosomes from activated platelets. Blood. 2006; 107: 3907-11.

27. Helley D, Banu E, Bouziane A, Banu A, Scotte F, Fischer AM, et al. Platelet microparticles: a potential predictive factor of survival in hormone-refractory prostate cancer patients treated with docetaxel-based chemotherapy. Eur Urol. 2009; 56: 479-84.

28. Lo Cicero A, Stahl PD, Raposo G. Extracellular vesicles shuffling intercellular messages: for good or for bad. Curr Opin Cell Biol. 2015; 35: 69-77.

29. Turpin D, Truchetet ME, Faustin B, Augusto JF, Contin-Bordes C, Brisson A, et al. Role of extracellular vesicles in autoimmune diseases. Autoimmun Rev. 2016; 15: 174-83

30. Stoorvogel W. Resolving sorting mechanisms into exosomes. Cell Res. 2015; 25: 531-2.

31. Hurley JH. ESCRTs are everywhere. EMBO J. 2015; 34: 2398-407.

32. Abels ER, Breakefield XO. Introduction to Extracellular Vesicles: Biogenesis, RNA Cargo Selection, Content, Release, and Uptake. Cell Mol Neurobiol. 2016; 36: 301-12

33. Colombo M, Raposo G, Thery C. Biogenesis, secretion, and intercellular interactions of exosomes and other extracellular vesicles. Annu Rev Cell Dev Biol. 2014; 30: 255-89.

34. Liu ML, Scalia R, Mehta JL, Williams KJ. Cholesterol-induced membrane microvesicles as novel carriers of damage-associated molecular patterns: mechanisms of formation, action, and detoxification. Arterioscler Thromb Vasc Biol. 2012; 32: 2113-21.

35. Gangalum RK, Atanasov IC, Zhou ZH, Bhat SP. AlphaB-crystallin is found in detergent-resistant membrane microdomains and is secreted via exosomes from human retinal pigment epithelial cells. J Biol Chem. 2011; 286: 3261-9.

36. Crescitelli R, Lasser C, Szabo TG, Kittel A, Eldh M, Dianzani I, et al. Distinct RNA profiles in subpopulations of extracellular vesicles: apoptotic bodies, microvesicles and exosomes. J Extracell Vesicles. 2013; 2.

37. Flaumenhaft R, Mairuhu AT, Italiano JE. Platelet- and megakaryocyte-derived microparticles. Semin Thromb Hemost. 2010; 36: 881-7.

38. Italiano JE, Jr., Mairuhu AT, Flaumenhaft R. Clinical relevance of microparticles from platelets and megakaryocytes. Curr Opin Hematol. 2010; 17: $578-84$

39. Heijnen HF, Schiel AE, Fijnheer R, Geuze HJ, Sixma JJ. Activated platelets release two types of membrane vesicles: microvesicles by surface shedding and exosomes derived from exocytosis of multivesicular bodies and alpha-granules. Blood. 1999; 94: 3791-9.

40. Dovizio M, Alberti S, Sacco A, Guillem-Llobat P, Schiavone S, Maier TJ, et al. Novel insights into the regulation of cyclooxygenase-2 expression by platelet-cancer cell cross-talk. Biochem Soc Trans. 2015; 43: 707-14.

41. Aatonen MT, Ohman T, Nyman TA, Laitinen S, Gronholm M, Siljander PR. Isolation and characterization of platelet-derived extracellular vesicles. J Extracell Vesicles. 2014; 3.

42. Chong JJ, Yang X, Don CW, Minami E, Liu YW, Weyers JJ, et al. Human embryonic-stem-cell-derived cardiomyocytes regenerate non-human primate hearts. Nature. 2014; 510: 273-7.

43. Ruiz M, Cosenza S, Maumus M, Jorgensen C, Noel D. Therapeutic application of mesenchymal stem cells in osteoarthritis. Expert Opin Biol Ther. 2016; 16: 33-42.

44. Basu J, Ludlow JW. Cell-based therapeutic products: potency assay development and application. Regen Med. 2014; 9: 497-512.

45. Guthrie K, Bruce A, Sangha N, Rivera E, Basu J. Potency evaluation of tissue engineered and regenerative medicine products. Trends Biotechnol. 2013; 31: 505-14.

46. Ohnishi S, Sumiyoshi H, Kitamura S, Nagaya N. Mesenchymal stem cells attenuate cardiac fibroblast proliferation and collagen synthesis through paracrine actions. FEBS Lett. 2007: 581: 3961-6.

47. Barile L, Lionetti V, Cervio E, Matteucci M, Gherghiceanu M, Popescu LM, et al. Extracellular vesicles from human cardiac progenitor cells inhibit cardiomyocyte apoptosis and improve cardiac function after myocardial infarction. Cardiovasc Res. 2014; 103: 530-41.

48. Garcia NA, Ontoria-Oviedo I, Gonzalez-King H, Diez-Juan A, Sepulveda P. Glucose Starvation in Cardiomyocytes Enhances Exosome Secretion and Promotes Angiogenesis in Endothelial Cells. PLoS One. 2015; 10: e0138849.

49. Li X, Chen C, Wei L, Li Q, Niu X, Xu Y, et al. Exosomes derived from endothelial progenitor cells attenuate vascular repair and accelerate 
reendothelialization by enhancing endothelial function. Cytotherapy. 2016; 18: 253-62.

50. Teng X, Chen L, Chen W, Yang J, Yang Z, Shen Z. Mesenchymal Stem Cell-Derived Exosomes Improve the Microenvironment of Infarcted Myocardium Contributing to Angiogenesis and Anti-Inflammation. Cell Physiol Biochem. 2015; 37: 2415-24.

51. Akyurekli C, Le Y, Richardson RB, Fergusson D, Tay J, Allan DS. A systematic review of preclinical studies on the therapeutic potential of mesenchymal stromal cell-derived microvesicles. Stem Cell Rev. 2015; 11: 150-60.

52. Gentile P, Scioli MG, Bielli A, Orlandi A, Cervelli V. Concise Review: The Use of Adipose-Derived Stromal Vascular Fraction Cells and Platelet Rich Plasma in Regenerative Plastic Surgery. Stem Cells. 2017; 35: 117-34.

53. Varon D, Shai E. Role of platelet-derived microparticles in angiogenesis and tumor progression. Discov Med. 2009; 8: 237-41.

54. Hayon Y, Dashevsky O, Shai E, Brill A, Varon D, Leker RR. Platelet microparticles induce angiogenesis and neurogenesis after cerebral ischemia. Curr Neurovasc Res. 2012; 9: 185-92.

55. Hayon Y, Dashevsky O, Shai E, Varon D, Leker RR. Platelet microparticles promote neural stem cell proliferation, survival and differentiation. J Mol Neurosci. 2012; 47: 659-65.

56. Hayon Y, Shai E, Varon D, Leker RR. The role of platelets and their microparticles in rehabilitation of ischemic brain tissue. CNS Neurol Disord Drug Targets. 2012; 11: 921-5.

57. Torreggiani E, Perut F, Roncuzzi L, Zini N, Baglio SR, Baldini N. Exosomes: novel effectors of human platelet lysate activity. Eur Cell Mater. 2014; 28: 137-51; discussion 51.

58. Guo SC, Tao SC, Yin WJ, Qi X, Yuan T, Zhang CQ. Exosomes derived from platelet-rich plasma promote the re-epithelization of chronic cutaneous wounds via activation of YAP in a diabetic rat model. Theranostics. 2017; 7: $81-96$.

59. Tao SC, Yuan T, Rui BY, Zhu ZZ, Guo SC, Zhang CQ. Exosomes derived from human platelet-rich plasma prevent apoptosis induced by glucocorticoid-associated endoplasmic reticulum stress in rat osteonecrosis of the femoral head via the Akt/Bad/Bcl-2 signal pathway. Theranostics. 2017; 7: 733-50.

60. Pak J, Lee JH, Jeon JH, Lee SH. Complete resolution of avascular necrosis of the human femoral head treated with adipose tissue-derived stem cells and platelet-rich plasma. J Int Med Res. 2014; 42: 1353-62.

61. Martin JR, Houdek MT, Sierra RJ. Use of concentrated bone marrow aspirate and platelet rich plasma during minimally invasive decompression of the femoral head in the treatment of osteonecrosis. Croat Med J. 2013; 54: 219-24

62. Varki A. Trousseau's syndrome: multiple definitions and multiple mechanisms. Blood. 2007; 110: 1723-9.

63. Gasic GJ, Gasic TB, Stewart CC. Antimetastatic effects associated with platelet reduction. Proc Natl Acad Sci U S A. 1968; 61: 46-52.

64. Karpatkin S, Pearlstein E, Ambrogio C, Coller BS. Role of adhesive proteins in platelet tumor interaction in vitro and metastasis formation in vivo. J Clin Invest. 1988; 81: 1012-9.

65. Chechlinska M, Kowalewska M, Nowak R. Systemic inflammation as a confounding factor in cancer biomarker discovery and validation. Nat Rev Cancer. 2010; 10: 2-3.

66. Pucci F, Rickelt S, Newton AP, Garris C, Nunes E, Evavold C, et al. PF4 Promotes Platelet Production and Lung Cancer Growth. Cell Rep. 2016; 17: 1764-72.

67. van Es N, Sturk A, Middeldorp S, Nieuwland R. Effects of cancer on platelets. Semin Oncol. 2014; 41: 311-8.

68. Janowska-Wieczorek A, Wysoczynski M, Kijowski J, Marquez-Curtis L, Machalinski B, Ratajczak J, et al. Microvesicles derived from activated platelets induce metastasis and angiogenesis in lung cancer. Int J Cancer. 2005; 113; 752-60.

69. Labelle M, Begum S, Hynes RO. Direct signaling between platelets and cancer cells induces an epithelial-mesenchymal-like transition and promotes metastasis. Cancer Cell. 2011; 20: 576-90.

70. Sunderland N, Skroblin P, Barwari T, Huntley RP, Lu R, Joshi A, et al. MicroRNA Biomarkers and Platelet Reactivity: The Clot Thickens. Circ Res. 2017; 120: 418-35.

71. Tao SC, Guo SC, Li M, Ke QF, Guo YP, Zhang CQ. Chitosan Wound Dressings Incorporating Exosomes Derived From MicroRNA-126-Overexpressing Synovium Mesenchymal Stem Cells Provide Sustained Release of Exosomes and Heal Full-Thickness Skin Defects in a Diabetic Rat Model. Stem Cells Transl Med. 2016.

72. Goetzl EJ, Goetzl L, Karliner JS, Tang N, Pulliam L. Human plasma platelet-derived exosomes: effects of aspirin. FASEB J. 2016; 30: 2058-63.

73. Elwood PC, Morgan G, Pickering JE, Galante J, Weightman AL, Morris D, et al. Aspirin in the Treatment of Cancer: Reductions in Metastatic Spread and in Mortality: A Systematic Review and Meta-Analyses of Published Studies. PLoS One. 2016; 11: e0152402

74. Nguyen JT, Koerper MA, Hess CP, Dowd CF, Hoffman WY, Dickman M, et al. Aspirin therapy in venous malformation: a retrospective cohort study of benefits, side effects, and patient experiences. Pediatr Dermatol. 2014; 31: $556-60$

75. Johnson KE, Forward JA, Tippy MD, Ceglowski JR, El-Husayni S, Kulenthirarajan R, et al. Tamoxifen Directly Inhibits Platelet Angiogenic Potential and Platelet-Mediated Metastasis. Arterioscler Thromb Vasc Biol. 2017.
76. Hood JL. Post isolation modification of exosomes for nanomedicine applications. Nanomedicine (Lond). 2016; 11: 1745-56.

77. Moreno-Gonzalo O, Villarroya-Beltri C, Sanchez-Madrid F. Post-translational modifications of exosomal proteins. Front Immunol. 2014; 5: 383.

78. Trivedi M, Talekar M, Shah P, Ouyang Q, Amiji M. Modification of tumor cell exosome content by transfection with wt-p53 and microRNA-125b expressing plasmid DNA and its effect on macrophage polarization. Oncogenesis. 2016; 5: 250 